\title{
Managed Care Concepts Prominently Featured in Innovative Management Programs at Duquesne University
}

$\mathrm{T}$ he current health care environment can be characterized this way: Do more with less and be nicer about it.

Given this reality, the management skills, behaviors, techniques, models, theories, and insights required to deliver pharmaceutical products and services efficiently take on critical importance. Faculty members at the Mylan School of Pharmacy at Duquesne University have noticed in conversations with many practitioners, in all kinds of practice settings, that the practitioners regret that they were not exposed to more courses in management, marketing, and finance while in school. These conversations, coupled with intuition, experience, and an understanding of the marketplace and the demands of surviving in that marketplace have led the Mylan School to develop three new programs in the past 18 months. These programs are designed to meet the needs of students- both entrylevel Doctor of Pharmacy (Pharm.D.) students and practitioners- for management and marketing skills. The programs are the management concentration for Pharm.D. students and an executive program based on management certificates for practitioners, and a Master of Science (M.S.) program in Pharmacy Administration developed to meet the demands for graduate education in social and behavioral disciplines related to marketing and management.

\section{- The Management Concentration}

The entry-level Pharm.D. program was instituted at Duquesne in 1994. The first class to complete the program graduated in 2000. During the professional phase of the program students take 134 credit hours of required didactic and experiential courses. Within these are required courses in Management (five hours), Communication (three hours), American Health Care Systems (three hours), Pharmacy Law (two hours), and
Advanced Law and Ethics (three hours). In the revised American Health Care Systems course, students are exposed to concepts in managed care pharmacy, with 10 lecture hours specifically on insurance and risk management, basic managed care principles and policies, and the Medicare and M edicaid systems. The last eight to nine classroom hours are spent reviewing basic principles of pharmacoeconomics. Students also take 10-13 hours of professional elective credits during their final two years in the program. Five new electives have been developed to take advantage of these open credit hours. Those electives are as follows:

Health Care Economics: the application of microeconomic theory to decision making in the health care arena. Students participate in both informal and formal compulsory debates on issues such as managed care and the appropriate rationing of health care resources, the effects of technology on the supply of and demand for pharmacists, and the integration of economics and value judgments into the proper structure and design of prescription drug benefits.

Financial Management: basic and advanced concepts in accounting and finance to assist students in business operations. Students perform projects enabling them to better understand capital budgeting and allocative decisions, techniques to evaluate the viability of programs, and initial considerations in designing a new program or cognitive service.

Marketing and Customer Service: the integration of basic marketing theory and management principles to teach students how to attract and retain customers. Peer-reviewed readings and projects deal with issues such as attracting customers to new services, recovering from service failures, and empowering employees to take care of customers.

Pharmacoeconomics: further application of basic concepts provided in the
American Health Care Systems course. Students critically evaluate the literature and develop a proposal for a cost-effectiveness evaluation of a new drug or service and give a poster presentation of this proposal that is open to the public.

Advanced Managed Care Principles and Policies: a very detailed examination of managed care and pharmacy benefits management. Students attend weekly seminars given by persons employed in the field, including insurers, administrators from pharmacy benefit management companies (PBM s), managed care liaisons from the pharmaceutical industry, and diplomats from the Academy of $M$ anaged Care Pharmacy (AMCP).

Students are not required to take all five of these courses but may replace one of them with any of a number of relevant courses from the School of Business or the Rangos School of Health Sciences. At the completion of the five electives students are awarded a certificate for a management concentration.

At its first offering, seven students enrolled in and completed the management concentration. In the current sixth-year class, 25 students from a class of 123 are on schedule to complete the management concentration; in the current fifth-year class, 48 students from a class of 143 are on schedule to complete the program. Obviously, the program has been well received by the students. The test of the value of the management concentration lies in the future, in the performance of these students as they move through the ranks of the pharmacy profession.

\section{The Management Certificate}

Practitioners who want to enhance their management skills often have a problem: They need more information than can be provided through continuing education (CE) programs, but do not have the time or interest to enroll in a full academic program such as a Master of Business Administration program.

Continued on page 96 
Faculty members are currently active in

\section{research projects with direct implications for}

\section{managed care pharmacy and the rational and}

cost-effective use of drug therapies.

The Management Certificate at Duquesne is an alternative to these two choices. In the spring of 2000 the American Council on Pharmaceutical Education granted approval to the Mylan School of Pharmacy to offer a certificate in management- the first such certificate in the nation.

The management certificate specifically focuses on personnel management and human resources. This program focuses on managing conflict, change, motivation, and performance appraisal and is targeted at practicing pharmacists in community and health systems, as well as nonpharmacists employed within the industry in management positions. The certificate requires 30 hours to complete, 16 of which are contact hours. Outside readings and written assignments are completed in the remaining 14 hours. Inclass contact hours emphasize discussion, demonstrations, role-play, and small group exercises.

The focus of the certificate is applied; theory is minimized. Further certificate programs are under development in financial management, strategic planning, and marketing and customer service. In addition to being awarded a certificate upon completion of each program, participants will be awarded CE credits.

\section{- The Master's Degree Program}

In the fall 2000 academic semester, the school's first M.S. class in Pharmacy Administration began taking courses and initiating their research projects. Students choose between the non-thesis and thesis programs. Requirements for completing the non-thesis track include 30 hours of didactic courses and 3 credit hours of "special problems" in which the student completes an applied research problem appropriate for his or her primary work environment. The thesis track is comprised of 24 credit hours of didactic course work and 9 credit hours toward completion of the thesis.

Students may choose one of four faculty members to direct their thesis projects. Each of these faculty members is currently active in research projects with direct implications for managed care pharmacy and the rational and cost-effective use of drug therapies. Shane Desselle, Ph.D., uses advanced psychometric techniques to develop instruments that may be used to assess member satisfaction with prescription drug coverage, and is currently researching other issues related to prescription drug benefits design. Vincent Giannetti, Ph.D., investigates the ethical distribution of pharmaceuticals and other health products and services in managed care and other populations, and examines counseling behaviors of pharmacists in a variety of settings. Michael Miller, M.S., our resident pharmacoeconomist, evaluates the quality of governmentsponsored programs designed to increase the access of prescription drugs to indigent populations. David Tipton, Ph.D., is developing a set of protocols for practitioners to use in delineating customerservice strategies for new cognitive services; he also seeks to uncover the most appropriate methods to deal with service mistakes by pharmacists. Graduate students are obviously afforded many choices from a group of faculty members who are diverse in their interests yet focused on advancing the profession of pharmacy and the rational use of drug therapy by patients.

The entry-level management concentration and master's program have been dovetailed nicely for current students. Courses taken during the management concentration are all applicable toward a master's degree, as long as students complete additional assignments when they take the courses as undergraduates.

\section{- Conclusion}

The Duquesne University Mylan School of Pharmacy Department of Pharmacy Administration now has three programs for entry-level students, graduate students, and practitioners to gain insights related to marketing, management, and the social and behavioral aspects of pharmacy, particularly as they apply toward managed care pharmacy practice.

David J. Tipton, Ph.D., and Shane P. Desselle, Ph.D., are Assistant Professors of Pharmacy Administration, Mylan School of Pharmacy, Duquesne University, Pittsburgh, PA. 